\title{
La asignación universal por hijo como política de inclusión social y educativa en la provincia de Córdoba desde la perspectiva de los actores
}

\author{
The universal allowance for child as a policy of social and \\ educational inclusion in the Province of Córdoba from the \\ actors' perspective
}

María Paula Juárez ${ }^{1}$

Viviana Macchiarola ${ }^{2}$

\begin{abstract}
Resumen: El artículo que se presenta a continuación ofrece resultados de un estudio sobre la implementación de la política social asignación universal por hijo (AUH) y sus aportes a la inclusión educativa, desarrollado a partir de la experiencia de cinco escuelas urbano marginales de la provincia de Córdoba, desde la perspectiva de los actores involucrados. Se trabajan algunas hipótesis evaluativas y categorías analíticas vinculadas a los usos de la AUH y los cambios que genera, así como su gestión y los problemas emergentes. La investigación ofrece aportes a los fines de orientar acciones dirigidas a la mejora y profundización de la implementación de este programa, creado con el propósito de contribuir a una mayor justicia social y educativa.
\end{abstract}

Palabras clave: política social, desigualdad social, derecho a la educación.

\footnotetext{
${ }^{1}$ Doctora en Psicología. Magíster en Ciencias Sociales. Magíster en Iniciación a la Investigación en Psicología de la Comunicación, Interacción Social y Desarrollo Humano. Diploma de Estudios Avanzados en Psicología Evolutiva y de la Educación. Licenciada en Psicopedagogía. Docente de la Universidad Nacional de Río Cuarto. Investigadora Asistente del Consejo Nacional de Investigaciones Científicas y Técnicas, Río Cuarto, Córdoba, Argentina. Correo electrónico: mpaulajuarez@gmail.com.

2 Doctora en Educación. Diploma de Estudios Avanzados. Profesora en Ciencias de la Educación. Docente de la Universidad Nacional de Río Cuarto, Córdoba, Argentina. Correo electrónico: macchiarolav@gmail.com.
}

Diálagos Pedagágicas. ISSN en línea: 2524-9274.

Año XVII, No 34, octubre 2019 - marzo 2020. Pág. 37-60.

DOI: http://dx.doi.org/10.22529/dp.2019.17(34)03 / Recibido: 26-02-2019 / Aprobado: 25-07-2019. 


\begin{abstract}
This study offers results from an analysis of the implementation of the social policy universal allowance for children (UAC) and its contributions to educational inclusion, based on the experience of five marginal urban schools in the Province of Córdoba, from the perspective of the involved actors. We work with some evaluative hypotheses and analytical categories related to the uses of the UAC and the changes it creates, as well as its management and emerging problems. The research offers contributions to guide actions aimed at improving and deepening the implementation of this program, whose purpose is contributing to a greater social and educational justice.
\end{abstract}

Key words: social policy, social inequality, right to education.

Haciéndose y rehaciéndose en el proceso de hacer la historia [...] mujeres y hombres, convirtiéndose en seres de inserción en el mundo... terminaron por tener en el sueño el motor de la historia. No hay cambio sin sueño, como no hay sueño sin esperanza.

- Freire, 1993, p. 87 -

\title{
Presentación
}

El artículo que se presenta a continuación ofrece resultados de un estudio sobre la implementación de la política social asignación universal por hijo (AUH) y sus aportes a la inclusión educativa. El trabajo de campo de la investigación que da originen a este artículo fue realizado en escuelas de la provincia de Córdoba en el período marzo a julio de 2014. Su finalidad fue construir algunas hipótesis evaluativas y categorías analíticas que orienten acciones para mejorar y profundizar la implementación de este programa que se originó para lograr una mayor justicia social y educativa.

El estudio se abordó desde la perspectiva de la educación como un derecho, lo que implica que el estado garantice la inclusión social y educativa. La inclusión social refiere al acceso al trabajo, a condiciones de vida digna, a la ciudadanía, al pleno ejercicio de derechos políticos y a la participación en el espacio público (Dyson, 2001). La inclusión supone el acceso y la participación de los individuos y los grupos en las esferas económica, política y cultural de la sociedad. Siguiendo el pensamiento de Castel (1995), no es un estado cristalizado, sino parte de un proceso conflictivo y complejo de integración social donde existen gradaciones entre exclusión-vulnerabilidad-inclusión.

Por su parte, la inclusión/exclusión educativa refiere a una cuestión de distribución de bienes materiales y simbólicos (como la educación) y de derechos. Blooth (1998, en Parrilla Latas, 2002) y Dyson (2001) entienden la inclusión educativa como proceso de participación más que como mero acceso, incorporación o integración de todos a la escuela sin que se garanticen iguales condiciones y metas. Esta perspec- 
tiva de análisis entiende la inclusión como aquella que potenciaría la participación de los estudiantes en los procesos educativos y que reduciría su exclusión del currículo común, de la cultura y de la comunidad. En este marco, la inclusión supone crear condiciones y procesos sociales y pedagógicos que favorezcan la igualdad de oportunidades para el acceso y permanencia en los procesos educativos, con aprendizajes con significado y sentido y para el consecuente egreso (Macchiarola, Martini, Montebelli \& Mancini, 2018, Perassi \& Macchiarola, 2018).

Krichesky (2009) sitúa el concepto de inclusión en el marco de las nociones de justicia educativa, igualdad y en la idea del niño o de la niña como sujetos de derecho. Sendón (2012) estudia los diversos significados que asume la inclusión escolar para los actores y otorga sentidos diferentes a las trayectorias educativas. Uno de esos significados es la inclusión como política social que enfatiza el papel de la escuela en la contención social cuando se coartan sus posibilidades de inclusión en otros espacios.

Estos conceptos constituyen el marco que orienta la construcción e interpretación de los datos del estudio.

Asimismo, diversas investigaciones se han realizado en torno a la implementación de la AUH en nuestro país, en sus distintas regiones, que han dado cuenta de cómo esta política social asume múltiples sentidos en los contextos y escenarios en donde se dinamiza.

Arcidiácono, Carmona Barrenechea y Straschnoy (2011) abordan diferentes aspectos de la AUH y advierten, en la implementación de la política, su carácter difuso entre las prestaciones clásicas de la seguridad social y los programas de transferencia condicionada de ingresos (PTCI) tradicionales de la asistencia social; reconocen tensiones y problematizan aspectos de la AUH en cuanto a su diseño y a las concepciones teóricas que la atraviesan desde el campo de la política social.

Bustos, Giglio y Villafañe (2012) estudian el impacto de la AUH en las provincias argentinas y registran desigualdades en las distintas regiones del país. Parten de la necesidad de precisar estas disparidades, que se concretan en indicadores demográficos, económicos y sociales, para avanzar en un análisis de la focalización y cobertura de la política y para atender a los impactos que genera en los ingresos y la participación económica de los miembros del hogar.

Gluz y Rodríguez Moyano (2013) analizan la política de la AUH en la provincia de Buenos Aires, reconocen los sentidos que asume a partir de los procesos de apropiación de los actores escolares y advierten que, más allá de los avances en términos de ampliación de derechos, se conservan mecanismos de control ligados a medidas asistenciales que terminan obturando genuinos procesos de inclusión escolar.

Agis, Cañete y Panigo (2013) realizaron una investigación entre 2009 y 2010, cuyo objetivo fue desarrollar un análisis de variación conjetural para anticipar el impacto de la AUH a partir de indicadores relacionados con cuatro dimensiones centrales del bienestar social como pobreza, indigencia, desigualdad y vulnerabi- 
lidad relativa. Se obtuvo como principal resultado que todos los indicadores de bienestar social examinados experimentarían una notable mejoría, especialmente en las regiones más carenciadas del país.

Particularmente, el aporte de nuestro estudio se focaliza en el análisis del vínculo de esta política social con la escolarización en cinco instituciones de nivel primario de la provincia de Córdoba y enfatiza la perspectiva de los actores involucrados.

\section{Acerca del problema de investigación}

En Argentina, en octubre de 2009, por decreto del Poder Ejecutivo № 1602 , se inicia la implementación de la asignación universal por hijo para protección social $(A U H)$ como un instrumento de política social orientada hacia la ampliación de los derechos de los sectores más vulnerables de la población. Este instrumento promueve, entre otras intenciones, la incorporación de los niños y jóvenes al sistema educativo como una condición imprescindible para la recepción del beneficio social. Consiste en una política que otorga una prestación monetaria no contributiva similar a la asignación familiar que reciben los hijos de los trabajadores formales.

Los fundamentos señalan la necesidad de "adoptar políticas públicas que permitan mejorar la situación de niñas, niños y adolescentes en situación de vulnerabilidad social, contemplando a su vez, la situación de quienes no se encuentran amparados por el Régimen de Asignaciones Familiares" (Argentina. Poder Ejecutivo Nacional, 2009, p. 1). De este modo se crea:

Un subsistema no contributivo de Asignación Universal por Hijo para Protección Social, destinado a aquellos niños, niñas y adolescentes residentes en la República Argentina, que no tengan otra asignación familiar prevista por la presente ley y que pertenezcan a grupos familiares que se encuentren desocupados o se desempeñen en la economía informal. (Argentina. Poder Ejecutivo Nacional, 2009, Art. 1)

La forma concreta en que se distribuye la AUH se explicita, a partir de la Resolución 11/2019 del Ministerio de Salud y Desarrollo Social, "el niño, niña, adolescente o persona mayor de edad con discapacidad y la persona que lo tiene a su cargo" (Argentina. Ministerio de Salud y Desarrollo Social, 2019, Capítulo 2, punto 3). Es decir, que la AUH es percibida por:

Quien resulte titular, cuando los integrantes del grupo familiar se encuentren desocupados, se desempeñen en la economía informal con un ingreso inferior al salario mínimo vital y móvil, sean monotributistas sociales, o sean trabajadores de casas particulares; y en todos los casos siempre que no se encuentren alcanzados por alguna de las incompatibilidades determinadas por la Administración Nacional de la Seguridad Social (ANSES). (Argentina. Ministerio de Salud y Desarrollo Social, 2019, Capítulo 2, punto 1)

La asignación es financiada con recursos de la Administración Nacional de Seguridad Social (ANSES) y, al momento de su creación, garantizaba un monto 
equivalente al de la asignación por hijo de los trabajadores en relación de dependencia. Su carácter universal está dado por la intención de generalizar un derecho hasta entonces limitado a los trabajadores formales.

En el citado decreto de creación, se menciona también que:

El otorgamiento del beneficio se somete a requisitos que deberán acreditarse para garantizar la universalidad y a la vez preservar la transparencia, condicionándolo al cumplimiento de los controles sanitarios obligatorios para menores y a la concurrencia al sistema público de enseñanza. (Argentina. Poder Ejecutivo Nacional, 2009, p. 1)

En este sentido, se trata de un programa de transferencias monetarias condicionadas.

Como señalan Agis, Cañete y Panigo (2013), debido a la condicionalidad de que los beneficiarios presenten los certificados de vacunación y de asistencia escolar requeridos, los primeros datos disponibles en el marco del Programa Trabajo y Empleo Urbanos del Centro de Estudios e Investigaciones Laborales del CONICET, en el período 2009-2010 y para todo el país, arrojaron resultados sumamente positivos con un aumento del $25 \%$ de la matrícula escolar y un incremento del $40 \%$ de los menores inscriptos en el seguro médico estatal Plan Nacer.

En este marco, el objetivo de la investigación fue interpretar el valor y el sentido que estudiantes y familias asignan a la AUH en sus trayectorias escolares. Los objetivos específicos fueron los siguientes: a) indagar las percepciones de los actores del Centro de Actividades Infantiles (CAI) sobre la implementación de la AUH, b) conocer los usos que se hacen de este beneficio, c) comprender los cambios que se perciben a partir de su implementación y d) detectar los problemas percibidos en su implementación.

\section{Metodología}

El enfoque metodológico utilizado fue predominantemente cualitativo en tanto buscó captar los significados que los actores otorgan a la política pública en estudio. Se intentó atender a la complejidad, singularidad y detalle de los sentidos e intenciones de los sujetos y ser sensibles al contexto social en el que se producen los procesos educativos.

El trabajo de campo se realizó en cinco escuelas ${ }^{3}$ ubicadas en zonas marginales de la ciudad de Córdoba, entre marzo y julio de 2014.

\footnotetext{
3 El estudio se realizó en las escuelas Alas Argentinas, Antártida Argentina, Maestra María Saleme, Gobernador Justo Páez Molina (estas cuatro, en Córdoba Capital) y Polo Godoy Rojo (en la localidad de Juárez Celman). En todas ellas, funcionan CAI. Se trata de otro instrumento de una política socioeducativa orientada a ampliar y fortalecer las trayectorias escolares y educativas de los niños en situación de alta vulnerabilidad social que necesitan acompañamiento pedagógico para acceder o completar sus estudios primarios.
} 
En cada uno de estos establecimientos, se realizaron entrevistas grupales a treinta estudiantes y entrevistas individuales a dos padres, a los directores y coordinadores de los CAI que funcionan en cada una de las cinco escuelas, así también como a veintidós maestros y talleristas.

Para el análisis de los datos, se emplearon estrategias de categorización en función de los ejes analíticos anteriores y las categorías emergentes de los datos. Se realizó una primera codificación abierta centrada en categorías analíticas y orientada por conceptos. Mediante un proceso de codificación, comparación, contrastación y el establecimiento de relaciones e inferencias, se construyeron síntesis conceptuales en términos de enunciados descriptivos, interpretativos y valorativos. Para este proceso, se empleó el software AtlasTI, versión 7.

\section{Usos y cambios percibidos por los actores a partir de la implementación de la AUH}

En el marco de la implementación de la $A U H$, los directores de las escuelas, coordinadores de los CAI, maestros, talleristas, alumnos y padres reconocen diversos usos y cambios como consecuencia de esta política.

Se hace referencia al uso de la AUH para dar cuenta de cómo las familias la emplean para su beneficio, así como el de sus hijos e hijas. Es el modo en que ejecutan o ejercen un rol de administradores de ese recurso y obran, de una manera determinada, sobre ese ingreso económico. En otras palabras, en qué lo ocupan, para qué lo destinan, en qué lo consumen y qué utilidad le otorgan a la $\mathrm{AUH}$.

Las dinámicas que asumen los diversos usos posibles de la AUH conllevan o propician distintos cambios, reconocidos por las familias, los niños y las niñas y son percibidos -o no- por los distintos actores sociales involucrados.

En este sentido, los datos emergentes del estudio permiten advertir un recorrido en las percepciones que los actores entrevistados han construido acerca de los usos y los cambios vinculados a la $A U H$, que van desde: 1) la no percepción o visualización parcializada de usos y cambios a partir de la $A U H, 2$ ) una percepción que subordina usos y cambios al rol de los padres, 3) una percepción de usos y cambios significativos, entre los que se distinguen, a su vez: 3.1) una percepción como ayuda o alivio a las necesidades económicas y sanitarias, 3.2) una percepción de usos y cambios de la AUH como aquellos que generan la permanencia en las escuelas y la mejora de las trayectorias escolares de los alumnos, 3.3) usos conscientes que impactan favorablemente en el estado anímico y la autoestima de los niños y las niñas y, finalmente, 4) la percepción de un paulatino proceso de concientización por parte de las familias en los usos y cambios propiciados por la AUH. Recorrido que desarrollaremos a continuación.

\subsection{Usos y cambios invisibilizados o parcializados}

Algunos actores entrevistados dan cuenta de una dificultad en visualizar, captar o percibir algún tipo de cambio o transformación a partir de la AUH. 
E: "¿Cree que influye de alguna manera la asignación universal por hijo en la permanencia de los chicos acá en el...?" T: [interrumpiendo] "¿Qué tiene que ver eso?" (71 T)

E: "¿Pensás que hubo cambios a partir de la AUH y del CAI en la escuela?" T: "En el caso de AUH no me puedo meter, no es mi área, no me puedo meter en el tema político, de la zona ni de afuera, no me correspondería a mí. Para eso se hace en la municipalidad y afuera se hacen estadísticas. No te puedo decir si ayuda o no, si ayuda mucho, si lógico aporta, haría falta más". (69 T)

Las docentes ofrecen respuestas que niegan la posibilidad de relacionar la asignación al hecho de que los alumnos y las alumnas permanezcan en la escuela, a partir de lo que ellas perciben semanalmente en el trabajo con ellos. Asimismo, podría inferirse de los testimonios una intencionalidad de mantenerse neutral a un posicionamiento político. Se advierte un trasfondo escéptico respecto del impacto de la política pública de la AUH y se deposita la responsabilidad de una posible evaluación de cambios percibidos solo a instancias gubernamentales. Algunos actores entrevistados dan un paso más al reconocer ciertos cambios a partir de la implementación de la AUH y ofrecen una concepción que la reduce solo a una recepción económico-adquisitiva por parte de las familias y los niños beneficiados.

"Influye en los recursos que ellos tienen. Tienen más recursos físicos, materiales, de [...] ropa y útiles escolares... No, no influye en decir: 'ah depende de eso que vengan', no...". (57 D)

Testimonios como el citado restringen la posibilidad de cambio solo a una percepción de la AUH como un incremento de recursos o ingresos de la familia, una cuestión más bien economicista o de influencia en lo material, que no tiene -para ellos- un correlato con el acceso a la escuela y la educación, a la salud, a la cultura. Lo desarrollado hasta aquí da cuenta de una visión un tanto restringida del impacto de la AUH en la inclusión educativa.

\subsection{Usos y cambios condicionados}

Algunas directoras, coordinadoras de CAI, maestras comunitarias y talleristas entienden que la posibilidad de que se presenten cambios a partir de la recepción de la AUH en familias y niños depende del uso, empleo o gestión que los adultos padres y madres- hagan de ella y ponen en duda, en algunos casos, su responsabilidad o papel como administradores de este recurso.

"Favorable sí. Va a depender de cómo se use eso...". (33 T)

"Nunca sabemos si realmente los padres la están usando para el niño... uno sabe que la cobran pero no se sabe el uso que le dan después". (6 MC)

\footnotetext{
${ }^{4}$ La expresión entre paréntesis identifica: a) el número de la entrevista y b) el actor entrevistado: E: estudiante, P: padre o madre, T: tallerista, M: maestro, D: director, Coo: coordinador del CAI y F: funcionario.
} 
Los actores reconocen que la posibilidad de generar cambios por parte de la AUH se halla supeditada al uso que las familias hagan de ella.

Muchos de ellos consideran que el uso de la AUH no recae directamente en el niño, sino en los propios padres y las propias madres, ponen en duda el empleo que hacen de ella y argumentan que la utilizan para adquirir bienes materiales propios de necesidades de adultos, como tarjetas para celulares, celulares nuevos y motos.

"Y en la actualidad yo veo mucha moto nueva, celulares nuevos con la asignación los chicos siguen estando como están y yo creo que la asignación tendría que venir acompañado del papá a la escuela". (9 P)

En esta línea, algunos actores entrevistados consideran que existe una incidencia negativa de la AHU en las familias desde el argumento que recibirla promueve el no trabajar, no buscar empleo, comodidad, pereza, etc.

"Creo que [...] a otros los ha hecho, que no creo que sea la mayoría, pero sí de dejar de buscar trabajo, que es la parte que tiene en contra la propuesta ¿no? [...] después está el otro que vos le decís "¿y no trabajás?" Y nooo porque... nosotros tenemos familias que viven puramente de subsidios y no deciden salir a trabajar, entonces viste, tanto subsidio es como que hace que vivan tan cómodamente". (87 D)

Algunos entrevistados consideran que se debería exigir a los padres y las madres una especie de trabajo comunitario como devolución por la AUH.

"Hay muchos casos que yo veo que no lo usan para los chicos [...] porque creo que por ahí el 'dar y dar y dar'... me parece que a una persona que le pagan la asignación podría hacer trabajos comunitarios, no sé... hacer cosas, que sea un ida y vuelta. Porque si vos solo das la gente se achancha". (34 T)

Creencias como la citada, que consideran que los padres deberían ofrecer a la sociedad su trabajo a cambio de la asignación o que fomentan la inacción, desconocen que la intencionalidad central que subyace a esta política pública es, justamente, la protección social como derecho universal de quienes -no por voluntad propia- están desempleados o se desempeñan en la economía informal y, por lo tanto, no perciben asignación familiar.

Argumentos como los planteados hasta aquí podrían asociarse a una interpretación asistencialista y "meritocrática" de la política social, propiciada por medios de comunicación hegemónicos que promueven un análisis restringido sobre la idea de subsidios del gobierno que siembran "ociosidad" en las poblaciones y que, por el contrario, debería tratarse de políticas ligadas al esfuerzo personal. Se trataría de concepciones vinculadas a un ferviente rechazo a políticas progresistas de inclusión social carentes de la capacidad de visualizar correlatos o impactos más amplios del potencial de dichas políticas y pone de manifiesto una percepción reduccionista de la política que le niega valor como derecho social para todos.

De este modo, advertimos cómo las representaciones, muchas veces "meritocráticas" y estigmatizantes de la pobreza, reinterpretan y transforman una política social que pretende universalizar derechos. 


\subsection{Usos y cambios significativos}

La AUH como un bálsamo frente a las necesidades materiales y sanitarias

Algunos actores reconocen en la AUH una posibilidad económica que resulta una especie de aplacamiento o alivio para las realidades de carencia y necesidades insatisfechas de estas familias.

"La asignación viene a sumarle un alivio económico para el padre, te das cuenta, y reforzar lo que se viene haciendo. Y todos los programas han servido para ayudar a que ellos se eleven más, son recursos te das cuenta, son recursos". (57 D)

"Tenemos familias que se acercan a decirnos, 'mirá seño no lo mando porque no tiene zapatillas pero ya el 12 o 13 ya cobro la plata de él y le voy a comprar las zapatillas', esos cambios, o 'mirá seño te traigo ahora un cuaderno porque te acordás que vos el mes pasado me diste un cuaderno porque él no tenía cuaderno, te devuelvo este para cuando le haga falta a otro nene' esas actitudes así se han ido logrando". (86 Coo)

Puede advertirse cómo este recurso económico, cuando está bien administrado, mejora la condición social de sus integrantes, impacta en su dignidad como personas y tiene un correlato en cambios y actitudes favorables que recaen en beneficio de otros. Asimismo, muchas madres entrevistadas reconocieron en la AUH una ayuda en los momentos de necesidad, especialmente en el caso de madres solas a cargo de varios hijos, o cuando uno de los cónyuges no tiene trabajo.

"Sí ayuda. Una porque tenés que mantener a los chicos, yo estoy sola y es duro. Porque ya no te alcanza para nada. Pero sí, te saca adelante". (68 P)

"Sí, la asignación por hijo te ayuda. No es mucho, pero te ayuda. Yo trabajo por hora. O sea que si no trabajás, con eso no podés mantener una criatura". (83 P)

"Para mi es una ayuda porque hay veces que mi marido no tiene trabajo... me ayuda me salva en comida, en las cosas de los chicos de la escuela". (51 P)

Estos padres y estas madres valoran la $\mathrm{AUH}$, ya que la reconocen como aporte que los libra del trance que suponen las necesidades insatisfechas y la perciben -de alguna manera- como un reaseguro para seguir andando en la cotidianidad de sus vidas.

Distintos actores entrevistados reconocen -en el uso que las familias hacen de la AUH- cambios que se advierten en distintos aspectos, que van desde la alimentación y la adquisición de vestimenta y útiles escolares, entre otros bienes materiales. Usos y cambios que se condicen con las utilidades reales que algunos padres y algunas madres expresan darle a la AUH.

"Para que haya comida en casa". (53 P)

"Saco 150 de cada uno y compro mercadería y después compro zapatillas y jogging para cada uno porque tengo dos". (13 P)

"Para comer, para estudiar, para la ropa. Si está enfermo para eso". (59 E)

Madres y padres entrevistados aluden usar la asignación para adquirir productos para la alimentación de sus hijos e hijas, necesidad vital para el desarrollo de los niños, la infancia y sus capacidades y un derecho en el seno de la familia. 
"Se nota en el desayuno, en esa necesidad que el niño llega y quiere sí o sí comer, quiere la leche, quiere el criollo, que en el recreo te pide comida, ise nota que no cenó! [...] el hambre de toda la tarde y toda la noche se ve, se ve en la mañana". (87 D)

Aun cuando hay madres que la priorizan como gasto de la asignación y aunque la maestra comunitaria considere que la AUH contribuye para la comida del hogar, la directora advierte que sigue habiendo niños que perciben la asignación y llegan a la escuela con hambre.

Por otro lado, los actores entrevistados reconocen un uso de la AUH vinculado a la adquisición de materiales escolares, la vestimenta necesaria para la vida escolar y el acceso a servicios de transporte, entre otros.

"Tengo una chiquita que va a un colegio especial, pagamos el transporte con eso, no es mucha la ayuda, pero". (29 P)

"Todo para los chicos [...]. Me resulto útil porque tuve que comprarles útiles a los tres, ahora que empezaron los tres. Para mi es una ayuda". (51 P)

"Mi mamá con eso lo usa para nosotros. A mí me compra los útiles, me compra la ropa para el colegio". (42 E)

Muchos de los actores entrevistados -como coordinadores de CAI, directoras de escuela y maestras comunitarias-, a partir de la AUH, perciben cambios vinculados al acceso a la salud.

"De por sí el control médico que se preocupan, pero no te puedo decir si realmente impactó al 100\%". (36 Coo)

"iYo estoy a favor de la asignación! [...] Porque es un chico que tiene un control médico". (37 D)

\section{Usos y cambios que estimulan la presencia y permanencia en la escuela}

Muchos actores entrevistados perciben que la AUH ha incidido en que los chicos permanezcan dentro de la escuela, que no queden marginados de ella, sino que la vivan en su cotidianidad como parte constituyente de sus vidas y que repercuta, de manera satisfactoria, en las propias trayectorias escolares de los niños y las niñas.

"Los ha organizado, los ha hecho volver a la escuela, los mantiene... a nosotros nos sirve porque a ellos los obliga a que los chicos vengan a la escuela, aunque sea no todos los días, pero sí sistemáticamente o por lo menos una forma de decir tres veces por semana vienen porque saben que sino después cuando viene el control de la libreta pueden tener problemas". (87 D)

"Hay más chicos, hay más chicos en las escuelas [...] se nota, se nota, en una escuela muy chiquita donde yo trabajo la matricula sube y es por los primeros grados". (99 T)

"A partir de la AUH se notan ciertos cambios [...] a principio de año traen ropa nueva y útiles nuevos. Creo que eso trae aparejados cambios en el rendimiento de los niños y sobre todo en la asistencia y permanencia de los niños en la escuela". (20 Coo) 
Sumado a la permanencia de los chicos en la escuela, algunos actores entrevistados reconocen que esta situación va acompañada de una presencia de los padres y las madres, lo que contribuye a la relación de la familia con la escuela.

"Yo creo que ayuda mucho en la manera en que vincula a la familia con las actividades escolares [...] el hecho de que en la escuela le pidan que asistan a la escuela, que la maestra comunitaria vaya a ver a la casa si el chico ha dejado de venir o si notamos que tiene algún problema [...] la maestra comunitaria cha ido?, ¿qué está pasando en la casa?, entonces este trabajo en conjunto hace que favorezca y que sin duda uno tenga un conocimiento que por ahí la escuela, no tuviera". (32 T)

\section{Usos y cambios que activan subjetividades}

Algunos actores entrevistados reconocen cómo el recibir un recurso económico bien administrado recae directamente en el niño para la satisfacción de sus necesidades de vestimenta, alimentación, juego, educación y salud y cómo ello, en consecuencia, incide favorablemente en su estado anímico en general.

"Desde el momento en que ellos ya vienen, se puede comprar lo que sea. Un zapatito mejor, una media más, vienen vos ves, por ahí traen hasta dos pesos para una merienda. Y les da una alegría, viste porque ellos se sienten bien, se sienten mejor". (43 MC1)

"Sirve para decirles es su hijo, y a usted le pagan para que su hijo estudie [...] usted tiene un compromiso con su hijo [...] el niño está feliz con venir a la escuela". (44 MC)

Se trata de niños y niñas que no solo ven disminuir sus carencias y penurias por necesidades, sino que -paulatinamente- comienzan a percibir la satisfacción el hecho de que se cubra algunas de sus necesidades, experimentan algún tipo de bienestar y regocijo, probablemente vinculado a su dignidad, a la vivencia del pleno derecho a la educación, la salud, la alimentación y el juego, entre otros.

Los testimonios dan cuenta de cómo, muchas veces, el recurso de la AUH es utilizado para actividades que inciden en un enriquecimiento y dinamización de las propias subjetividades de los niños y las niñas, como hacer danza, ir a maestra particular, realizar paseos o adquirir capital simbólico como libros y textos.

"Todo para los útiles de la escuela, por ahí ella le gusta hacer danza, este nosotros la enviamos una vez y por cuestiones de dinero no pudimos llevarla más y a ella le gusta todo eso, es más compramos todos los elementos indumentaria todo y bueno, fue unos meses y después no pudo ir más porque tuvimos que restringir gastos". (46 P)

"En lo educativo... quizás una mamá nos ha comentado que puede llevarlo a maestra particular, y tener así una ayuda extra". (95 M)

"Algunas veces mi mamá nos lleva al parque, a lugares con la plata". (60 E) 


\section{Usos y cambios que concientizan}

Las directoras, maestras y talleristas entrevistadas en el estudio reconocen que, en los últimos años de implementación de esta política, ha sido posible advertir un proceso de concientización por parte de las familias, padres y madres en el uso, así como en los cambios manifestados por ellos respecto a la $\mathrm{AUH}$, que ha sido acompañado por un trabajo de los educadores y actores institucionales.

"Ahora los papás ya entendieron qué función cumplía esto, al principio yo creo que ellos lo entendieron que era un dinero que les ingresaba y que ellos podían utilizar y hacer con eso lo que quisieran [...] ellos ahora han entendido que ese dinero es para sus hijos [...] se han dado cuenta de que lo necesitan sus hijos y que [...] tampoco les alcanza, pero por lo menos, y también ven que la plata que ingresa a la escuela para materiales ellos ven que los chicos lo utilizan". (86 Coo)

"Veo que ya llega fines de febrero y están comprando todo nuevo, comprándoles los útiles, porque cuentan con esa plata y saben que es para eso. [...] como que tomaron más conciencia de que eso no es para cualquier cosa, sino para el chico en la escuela". (97 NDC)

Se advierte, por parte de los actores entrevistados, un transitar de la AUH como política social que da cuenta de avances hacia una recepción más profunda y comprometida por parte de las familias. No obstante, sería posible preguntar: ¿qué sucedía los primeros tiempos de implementación de la política que las familias no asumían reflexivamente el empleo de la asignación?, ¿qué procesos sociales, políticos, económicos, culturales e intersubjetivos incidirán para que, en la actualidad, la asignación sea administrada con mayor compromiso y conciencia por parte de las familias?

Respecto al primer interrogante, podría pensarse que años de ausencia del Estado en el plano de políticas sociales y de iniciativas de corte asistencialista, que continuaban perpetuando un modelo de exclusión propio del neoliberalismo, incidieron en el sentimiento de abandono y aislamiento por parte de muchas familias de los sectores populares. En relación al período en estudio y para intentar avanzar en el segundo interrogante, la apuesta por políticas sociales sustentadas en lógicas inclusivas, de mayor contención y presencia del Estado, posiblemente, influyó en la dinámica cotidiana de la vida familiar y generó que padres y madres, desde un proceso paulatino pero progresivo, fueran ganando mayor injerencia y compromiso desde un acogimiento activo del recurso de la asignación. Ello, sumado a la visualización y reconocimiento que diferentes actores de las instituciones escolares hacen de los usos eficientes y los cambios conscientes por parte de las familias, los retroalimenta al motivarlos desde relaciones basadas en la confianza y la apuesta a estas familias.

Podría reconocerse así, de acuerdo a la denominación de Freire (1974), una "época transicional", que implica una marcha acelerada que lleva a la sociedad a nuevos cambios, nuevos temas y nuevas tareas, pero que aún conserva lo viejo, lo existente, lo aceptado, lo instituido, a la vez que va anunciando e instalando lo que viene, lo instituyente. Tiempos complejos en que no todo emerge como cambio genuino, sino que también es posible advertir detenimientos y estancamientos. 
"Yo creo que les ha dado un poco de seguridad decir 'tengo algo por lo menos todos los días o todos los meses seguro', creo que a muchos les permitió dejar de pensar que la única salida que tenían era salir a pedir o robar, por lo menos ellos saben que de alguna manera van a comer todo el mes [...]. Yo creo que las mamás que son solas con muchos hijos creo que les ha dado el alivio de decir 'bueno me puedo dedicar a mis hijos que sé que tengo qué darles' [...] en este caso les da la seguridad de decir 'bueno yo me dedico a llevar a mi chico a la escuela, vuelvo, le busco comida, mi trabajo es este, me están pagando para esto, lo voy a hacer', sí, sí, muchos de esos". (87 D)

El testimonio da cuenta de un cambio de percepción por parte de las familias, padres y madres al asumir -con mayor responsabilidad y obligación- su rol, acompañado y promovido por un papel docente activo que motiva y estimula este proceso.

Freire (1997) entiende la asunción como la acción que el sujeto hace de sí en una cierta forma de estar siendo gracias a la disponibilidad para el cambio de cuyo proceso se hace sujeto. Para el autor, este proceso se va haciendo más profundo en la medida en que engendra nuevas opciones, provoca rupturas, decisiones y nuevos compromisos, lo que se advierte en los testimonios de algunos padres y algunas madres que reciben la AUH. En este proceso, los educadores asumen un rol central al promover la toma de conciencia en el uso de la AUH.

"Esa plata es de ellos. Nosotros siempre le decimos lo que ellos cobran es para ellos [...] ayer una mamá me decía: 'Ayer cobré lo de los chicos y fui a pagar todo lo que me habían dado fiado' esa mamá... te digo que tiene a todos los hijos estudiando". (43 M)

"Cada uno de los papás asume esto de que por percibir eso tienen un poco más de obligación en esto de la colaboración en lo que hace a la escuela ¿no?, a que su hijo estudie, cumpla con lo que tiene que hacer, eh... por ese lado lo vería, como un compromiso que deben asumir más los padres más que los chicos" (71 T)

Esta concientización que los padres y las madres comienzan a ejercitar de sus propias vidas -y el sentido que la AUH adquiere en ellas- aparece como un camino que crea condiciones para que los derechos a la educación y a la salud sean ejercidos más allá de la existencia de la condicionalidad de la AUH.

\section{Gestión y problemas de la AUH}

La gestión de la AUH por parte de las escuelas manifiesta criterios comunes a todas las instituciones (vinculada a aquello que está instituido en la normativa de la política), así como criterios propios que suponen la realización de actividades particulares que asumen algunas instituciones y que son llevadas a cabo por sus actores. Asimismo, como administración que implica la realización de diligencias conducentes al logro de su cumplimiento genuino, la gestión de la AUH conlleva distintos problemas que emergen en el devenir de su implementación.

Los datos emergentes del estudio dan cuenta de: 1) estrategias de gestión tales como firma de libretas y acciones para promover la permanencia escolar, 2) 
articulación educación - salud para la gestión de la AUH y 3) problemas emergentes en la gestión de la AUH y mecanismos alternativos sugeridos por los actores para optimizar dicha gestión. Desarrollaremos estas características a continuación.

\subsection{Estrategias de gestión de la AUH}

Firma de libretas como criterio común de gestión de la AUH

La firma de libretas implica una dinámica de gestión de la AUH que se realiza anualmente para cada caso de niños beneficiarios y niñas beneficiarias. Al vencimiento, luego de un año de la fecha en que las familias han iniciado el trámite para cobrar la asignación, las libretas deben ser firmadas y se realiza nuevamente el trámite como una especie de renovación para continuar recibiendo el beneficio.

"Una vez al año [se firma la libreta] la fecha en que ellos han iniciado el trámite, al año de cada vez se lo tiene que hacer de vuelta el trámite para que no se les caiga el plan [...] ya si fuera una vez por mes tendríamos que buscarnos un secretario que firme porque es mucho el tiempo que te lleva, porque es mucho, lleva datos, lleva cosas... el nombre de la escuela, un código de la escuela, el grado del niño, si fue alumno regular el año anterior, bueno cosas básicas, te pregunta si fue alumno, si asiste regularmente". (87 D)

Los directivos consideran que la firma de libretas es una tarea ardua que les exige mucho tiempo dado que hay que completar planillas con distintos datos personales de los niños y sus familias. Frente a la hipotética situación de que la misma libreta debiera firmarse mensualmente, aluden que no sería posible y que requerirían de la ayuda de un secretario, como una especie de auxiliar administrativo para su tarea.

Para los actores entrevistados, la firma de libretas por la AUH es como uno de los instrumentos o medios que sirve para conseguir la asistencia y permanencia de los chicos en la escuela. Frente a aquellas situaciones en que las madres y/o los padres no los envían a la escuela, los directivos utilizan el argumento de "no firmar" como una especie de ultimátum si no se cumple con lo estipulado como acuerdo que implica la $\mathrm{AUH}$.

"Es un arma, una herramienta que nosotras usamos mucho, 'cuando vayas a firmar la libreta no te la voy a firmar si no'". (87 D)

Se reconoce, en estas expresiones, una especie de exigencia legítima que condiciona la acción del propio directivo con la acción propia de las madres y/o los padres de llevar -o no- a los niños y las niñas a la escuela.

"El año pasado mantuve conversaciones con gente del ANSES [...] mi posicionamiento fue que yo no iba a firmar las libretas si los niños no asistían a la escuela [...] yo me mantuve firme y me ha dado resultado porque les digo a los papás que los chicos tienen que estar inscriptos y 'respirando' en el aula para que les firme la libreta y los niños deben continuar asistiendo todo el año a la escuela. Si yo firmo las libretas es una declaración jurada de que esos niños asisten a la escuela y si no es así yo estaría falseando la información y estafando porque esa gente va a cobrar 
y no está cumpliendo con el requisito de mandar a sus hijos a la escuela. Me ligo más de un insulto por esto, pero tengo solvencia moral, tengo poder de gestión y autoridad dada por los años que hace que estoy en la escuela". (21 D)

Para algunos actores, la firma de libretas es un compromiso insoslayable por el que ellos dan su palabra. Consideran que el vivir la vida dentro de la escuela es una exigencia central e ineludible de esta política social. El no cumplimiento de ello por parte de algunos padres o algunas madres expone a los directivos a situaciones que oscilan entre no firmar y dejar a ese niño o esa niña sin su ingreso mensual (que se retiene en el ANSES hasta que la situación se regularice) o firmar e incurrir en un fraude o engaño al simular un hecho que no se condice con la realidad de estos niños y estas niñas.

"La libreta se firma, pero se firma sí o sí [...] nosotros no tenemos de dónde agarrarnos, esa libreta hay que firmárselas porque es dinero de sus hijos, tampoco se los podemos negar". (86 Coo)

A muchos directivos se les genera el dilema de firmar o no firmar. Algunos sienten que no es su deber decidir si un niño debe -o no- recibir este beneficio, otros lo asumen como una tarea que exige ética y moral para su cumplimiento y en algunos casos- colocan su propia trayectoria como argumento para justificar por qué no caer en situaciones que ellos consideran engañosas para que el niño o la niña cobre la asignación.

"Hay chicos que pasan días y no vienen [...] teníamos un nene en jardín [...] que no fue nunca y después la mamá quiso que le firmara la directora la asignación... o sea, tiene que ir a la escuela si quiere que le firmemos la asignación [...] Y bueno, me dice la directora 'pero si yo no le firmo no le dan la asignación'". (105 P)

Muchas veces, las mismas madres reclaman la situación en la que caen otras madres de no enviar a sus hijos a la escuela y las valoran como "irresponsables". Situaciones como la planteada ubican en una encrucijada a las docentes y los directivos, quienes consideran que los niños salen doblemente perjudicados de la situación: primero, por no haber sido enviados a la escuela y, segundo, porque la directora no firma la libreta y -en consecuencia- ni el niño ni su familia reciben el recurso de la $\mathrm{AUH}$.

Sumado a ello, los actores entrevistados advierten que algunos padres y algunas madres llevan a sus hijos a la escuela solo en vísperas de requerir que las libretas sean firmadas y así cumplir con el requisito que les permite cobrar la AUH. Aluden que, una vez que consiguen esta firma, los niños vuelven a abandonar transitoriamente la escuela.

\section{Creación de estrategias para sostener la permanencia escolar}

Los testimonios dan cuenta -también- de la generación de estrategias o herramientas que les permiten promover la asistencia y permanencia de los niños y las niñas en la escuela, tales como registrar las inasistencias no justificadas, visitar los hogares o llamar por teléfono a la familia cuando los niños no asisten. 
"La estrategia que tuvimos que usar 'miren que les vamos a anotar las injustificadas y el gobierno no les va a pagar más'. Esa estrategia provocó que manden a los chicos, y que se preocuparan... la estrategia que pensó la escuela para sostenerlos, y si una de las cosas que hace la maestra comunitaria son las visitas en la casa, llamamos por teléfono, les preguntamos por qué han faltado y si no atienden vamos a la casa". (80 M)

La posibilidad de que las inasistencias se registren como justificadas o injustificadas emerge frente a una realidad en la que los niños no asisten cotidianamente a la escuela sino de manera esporádica, casi fortuita, lo que problematiza a las docentes que advierten la dificultad para construir y sostener aprendizajes con continuidad en el tiempo. Asimismo, se revaloriza el lugar de la escuela como uno de los espacios pedagógicos privilegiados en la vida del niño en comparación con hogares donde la carencia, las privaciones y las necesidades son acuciantes y no se ofrecen las condiciones óptimas para el despliegue de sus posibilidades educativas.

Se advierte, en este tipo de estrategias o herramientas generadas por los actores institucionales, la intencionalidad de viabilizar, manejar o conducir -de manera satisfactoria- las distintas situaciones problemáticas que se presentan con las familias y los niños y las niñas.

\subsection{Articulación educación - salud para la gestión de la AUH}

Vinculado a lo anterior, al intentar hallar caminos convergentes en la gestión de la AUH por parte de las escuelas e instituciones de salud, se destaca un caso en el que, desde años anteriores a la implementación de la $A U H$, ya funcionaba -dentro de la escuela- el centro de salud de la comunidad. Con la implementación de la AUH, los actores de estas instituciones estrechan -aún más- sus vínculos y consolidan relaciones mediante la realización de acciones conjuntas y mancomunadas en la supervisión y control de la salud y la educación de los niños y las niñas que se benefician con la AUH.

"Nosotros tenemos en esta escuela otra fortaleza...que es esta doctora que en un momento llegó el dispensario a la escuela que hace 6-7 años que está trabajando, nosotras tenemos el dispensario acá [...] adentro de la escuela, en un aula de la escuela con salida al exterior tenemos el dispensario... [funciona] tooodos los días [...] la doctora es una persona [...] totalmente comprometida con los chicos de la escuela, entonces en materia de salud ¿qué pasó con la asignación universal?, acá nadie se le firma la libreta si no tenés la vacuna, el peso, es decir sí te voy a firmar pero tenés que hacer esto, esto y esto. Te voy a hacer la ficha médica [...] ella nos pasa a nosotros cuando vemos algo para allá, entonces en lo que respecta a la salud de los chicos que [...] esté protegida, para mí eso está buenísimo [...] Nosotros certificamos que los chicos vengan a clase [...] yo siempre les decía a los padres y antes de la asignación, vos decís de alguna manera tienen que estar en la escuela ¿por qué? Porque yo todo chico que está en la escuela veo si está sano, si está comido, qué está haciendo, iademás de estar aprendiendo hay una serie de factores que les da protección! y más con la asignación". (37 D) 
Si bien se lo reconoce como caso inédito, se constituye en un modelo para pensar su posibilidad de recreación, dado que se trata de un centro de salud que funciona en el interior de una escuela -con salida también a la comunidad-, cuyos trabajadores, maestras, enfermeros y médicos trabajan colaborativamente y articulados entre sí en pos de la salud y aprendizajes de los niños.

Esta situación da la posibilidad, por un lado, a los profesionales de la salud de conocer e interesarse -desde una concepción de salud integral (biopsicosocial)por las trayectorias escolares de sus niños consultantes y, por otro lado, la posibilidad que se le da a los educadores del estado de salud de sus alumnos: si están sanos, enfermos, si están recibiendo atención sanitaria, de qué tipo, si son atendidos los niños y sus familias, si acceden no sólo geográfica, jurídica o administrativamente a la salud, sino también simbólica y culturalmente.

De esta manera, la importancia de la asistencia y permanencia de estos niños en la escuela es doble o se multiplica exponencialmente, dado que se trata de un niño que es pensado por una directora de escuela y por una pediatra, ambas en diálogo permanente y que, gracias a ello, han construido un conocimiento de determinado niño en lo que hace a su salud, su alimentación, sus aprendizajes, sus intereses, actividades, su familia, su realidad, su contexto social.

Más allá del caso mencionado, otras escuelas entran en diálogo con los centros de atención primaria cercanos de la comunidad para realizar acciones sostenidas que inciden directamente en la gestión de la AUH.

"Tenemos mucho apoyo del centro de salud, las chicas, hay una asistente social, una psicopedagoga, la nutricionista y es como que ellas están trabajando muy bien en equipo entonces van teniendo en cuenta esto y nos van avisando "mirá esta familia tiene 5 chicos y están viniendo 3 no más y los otros 2 también tendrían que estar escolarizados". (86 Coo)

Se advierte cómo algunas escuelas se pliegan a las exigencias del sistema de salud y, a la inversa, el sistema de salud se acoge a las demandas del sistema educativo, para poner de manifiesto que -para percibir la AUH- la condición es tanto la atención de la salud del niño como su asistencia y permanencia en la escuela.

\subsection{Problemas emergentes en la gestión de la AUH}

\section{Problemas percibidos}

De la gestión de la $A U H$, surgen problemas que parecen deberse a conflictos de intereses de distintos actores sociales (estado, familias -padre, madre, niños- escuela -directivos, coordinadores de CAI, maestras, talleristas-) para su prosecución.

Los problemas identificados van desde el plano intrafamiliar al escolar y dan cuenta de hechos o circunstancias que dificultan la genuina consecución de la finalidad de la AUH y se manifiestan en el disgusto y preocupación de estos actores. 
En el plano intrafamiliar, se advierten problemáticas vinculadas a cuál de los cónyuges es el responsable del cobro de la asignación y cómo, para qué o quién la administra.

"En las familias hay disputas, sobre todo porque esta es una sociedad muy disgregada, digamos, de padres separados, a nosotros nos ha generado hasta conflictos 'qué le firmó a mi marido, que los chicos los tengo yo', 'que no le corresponde porque él se lo cobra y no me da nada', viste... cuando te viene el papá o mamá si no tenés una documentación de un juez o de algo no podés decir 'yo a vos no te doy o a vos sí [...] a mí me viene el papá con la libreta y yo al niño lo tengo escolarizado y yo le tengo que firmar porque cuál es la causa para negarme". (87 D)

"Yo tengo siete hermanitos. Mi papá cobra eso por mí, pero se lo da a otra criaturita que tiene por ahí". (89 E)

Se advierte cómo, especialmente alumnos y madres, manifiestan situaciones internas intrafamiliares que dan cuenta de manejos conflictivos en la administración de la AUH.

Por otro lado, algunos niños manifiestan expresiones de deseo respecto a las posibilidades y alcances que ofrece la $\mathrm{AUH}$ en relación a las propias problemáticas habitacionales.

"Mi mamá ahora cuando cobre mayo nos dijo que van a comprar el auto y nos van a hacer una pieza más [...] porque en una pieza está la cama grande de dos plazas y ahí duermen mi mamá y mi papá y después está la cama en la que duerme mi hermanito y después está mi cama en la que duermo yo y después está la otra pieza en la que duerme mi hermanito discapacitado y después está la cucheta en la que duerme el Javier y el Agustín. Y mi hermana se tira un colchón". (93 E)

El fragmento citado expresa una problemática que trasciende lo singular que vivencia una familia y se erige como un caso representativo de una problemática social propia de la pobreza, que se manifiesta aquí en el seno de una familia que recibe la AUH. La realidad de hacinamiento y precariedad habitacional que se describe, y que viven muchos niños y muchas niñas, sumada a la expresión de deseo respecto de la posibilidad de la AUH para revertir su realidad, dinamiza varias reflexiones.

Atribuir tal posibilidad de cambio a la AUH promueve consideraciones en un doble sentido. Por un lado, pensar lo distante que puede resultar la AUH -como política social orientada a satisfacer necesidades sanitarias, educativas, etc.- de la adquisición de ciertos bienes materiales (inmuebles, medios de transporte) o de la solución del problema de la pobreza. Por el otro, reflexionar acerca de que, para estos niños, si la AUH pudo "algo" (cambios significativos para ellos, como adquirir útiles, vestimenta, zapatillas, juguetes, alguna salida, paseo) quizás pueda "más", desde su esperanza arraigada en la manifestación del deseo, de ahí el pedirle más o atribuirle más posibilidades de cambio a ese recurso. La conciencia de un niño, la ingenuidad, lo deseado, lo esperado, sumados al hecho de recibir un tipo de respuesta por parte de un estado que resulta presente, se conjugan como condiciones propicias para esperar más de él. 
Por otro lado, y como contrapartida, para muchas madres y demás actores entrevistados, el monto económico de la AUH resulta un problema en la medida que es insuficiente para resolver las necesidades que se viven.

"Yo sinceramente a mí no me alcanza, no me alcanza porque son cinco entonces yo cobro por tres... que dividir también para los otros dos que me quedan". (105 P)

"ellos ya se han dado cuenta que lo necesitan sus hijos y que es una miseria que tampoco les alcanza, pero por lo menos, y también ven que la plata que ingresa a la escuela para materiales ellos ven que los chicos lo utilizan". (86 C)

Los actores consideran, por un lado, que se hace escaso el monto de la AUH cuando se tiene que dividir entre más hermanos; por el otro, que dicho monto resulta insuficiente para satisfacer lo necesario para el sustento o las necesidades que tienen estas familias numerosas, a las que les es difícil salir adelante aun percibiendo este recurso.

Otros actores reconocen el problema, quizás más preocupante, de aquellas familias que no pueden acceder a la AUH.

"Por ahí estamos viendo gente que tiene asignación y que no necesitaría y por ahí otros que yo te contaba que son de nacionalidad extranjera y que sí la necesitarían y que no la tienen [...] te preguntás cómo no hay más control en eso, como este lo recibe y aquel que realmente lo necesita no lo tiene, o porque no tiene el DNI". (3 C)

"Y sé que hay otras que lo necesitan y no acceden por esto... otras que son familias que no saben cómo hacer el trámite porque son analfabetos ¿se entiende?". (73 D)

"Para hacer este trámite... hay chicos que han venido, yo digo chicos, son jóvenes como vos, se han sentado en la escuela le han dicho 'dame la libreta, yo te la llevo te hago el trámite en el ANSES y te lo vuelvo a...' no fueron capaces de llegar a la escuela a decir 'yo no tengo', no, no, ini eso!" (87 D)

Los actores consideran que hay familias que necesitarían el aporte de la AUH pero que no pueden acceder a ella por distintos motivos como el no estar documentados, ser de nacionalidad extranjera, hallarse en condición de analfabetismo y desconocer cómo realizar el trámite, entre otras situaciones posibles. Asimismo, se destaca que, incluso en oportunidades en que trabajadores del ANSES llegaron al barrio para facilitar estas gestiones a las familias aún no beneficiadas, muchas de ellas no asistieron a la escuela para iniciar el trámite. Los actores atribuyen una falta de disposición ("no fueron capaces") de estas familias para acudir a la escuela e iniciar la gestión.

Por otro lado, los problemas que se identifican en el plano escolar se advierten en relación a demandas por un mayor control o una necesaria auditoría por parte de los entrevistados con respecto al funcionamiento de la AUH.

"Nosotros certificamos que los chicos vengan a clase [...] pero que sea alumno regular en el 2013 y que este cursando no me da mucho de decir ¿de qué manera fue alumno y está cursando?". (37 D)

"Tiene que estar bien observado 'si yo estoy dando esto, bueno ca quién se lo estoy dando?, ¿cómo se lo estoy dando? y ¿por qué?'". (99 T) 
"No estoy muy segura de que lo que reciben por la AUH lo gasten totalmente en los niños, pero no sé cómo se puede controlar". (21 D)

"Tenemos casos en que hay chicos que vienen no más a que le firmen la libreta, y después no vienen más [...] hay semanas que no vienen ni un día. Pero esa es nuestra realidad. En algunos casos ha dado resultados, que la asignación los favoreció, pero hay muchos casos en donde... los mandan para cobrar la asignación únicamente. Entonces ellos deben tener una regularidad escolar, por eso a lo mejor dos días de la semana lo mandan, los demás no... por eso no sé, hasta donde pensar que es tan buena la asignación familiar, en lo que sea la asistencia a clase ¿no?". (96 M)

Tal como se planteó al inicio en relación a la firma de libretas, los actores entrevistados reconocen que tal procedimiento es susceptible de distintos ardides por parte de las familias, de ahí que reconozcan este procedimiento como un problema que requeriría de mayor control.

Coincidimos con Gluz y Moyano (2013) en que estas expectativas de mayores controles sobre el cumplimiento de las condicionalidades de la AUH, en este caso educativas, que no se establecen para el cobro de las asignaciones familiares a los trabajadores formales, suponen mecanismos diferenciales, lo que tensiona o pone en cuestión la lógica de la asignación como derecho universal.

\subsection{Mecanismos alternativos para optimizar la gestión de la AUH}

Vinculado al último problema analizado en el apartado anterior, distintos actores reflexionan sobre la necesidad de un control más exhaustivo de la AUH que no se limite solo a la firma de libretas y que contemple distintos aspectos que se deberían tener en cuenta.

"Me parece que tendría que haber una persona en cada escuela, que diga [...] cómo está funcionando la asignación, si está funcionando la función que tienen que cumplir porque si todos los meses se está pagando un monto de plata para que los chicos vengan calzados, vestidos, con los útiles escolares, me parece que tiene que haber una persona que venga a ver qué pasa, por qué este nene no está trayendo las cosas si mensualmente está cobrando, por qué este nene no asiste a la escuela si está cobrando para que asista y que sean justificadas las faltas". (9 P)

"Creo que deberían establecer mecanismos de control que no sea necesariamente nosotros [...] deberían establecer mecanismos de control desde la nación... no sé, a través de trabajadores sociales o [...] por lo menos que... vean que asiste regularmente. Bueno entonces si tiene "buenos" y asiste regularmente se lo seguimos dando. [...] pero me parece que se verían mejores resultados si en esto hubiera un tipo de control o llámale monitoreo más que control, porque control suena como feo, pero como de monitoreo para... para conllevar a las familias a esta toma de conciencia de que es un beneficio para una cosa en particular y no otra, ime explico?" (73 D)

Los actores entrevistados contemplan la posibilidad de que se realice una especie de supervisión, monitoreo, registro de uso o amparo de la AUH que impli- 
que atender a aspectos como la asistencia e inasistencia de los alumnos y sus causas, la observación de necesidades que aún podrían seguir presentando -o no- los alumnos beneficiarios y el porqué, un seguimiento del rendimiento escolar que atienda a las calificaciones de los alumnos, el rol de los padres y las madres en el acompañamiento en las tareas escolares, su presencia y participación en las actividades escolares, entre otros.

Se piensa en la idea de "monitoreo" ejercido por una persona que guíe este proceso de administración y uso de la $\mathrm{AUH}$, como un ayudante que acompañe a las familias y a la escuela en las tareas, actividades y demandas que la AUH supone. En otras palabras, los actores avanzan y consideran que debería existir una persona exclusivamente dedicada a este trabajo; así, mencionan -por ejemplo- un trabajador social que atienda a estos aspectos.

Entendemos que estas propuestas que realizan los actores escolares para mejorar la gestión de la AUH están dirigidas a acompañar la política con procesos de evaluación permanente o monitoreo de su implementación, procesos ineludibles en la implementación de toda política pública para su retroalimentación y enriquecimiento permanente.

\section{Conclusiones: la AUH como tiempo de posibilidad y apuesta ineludible del Estado}

Desentrañar lo que la AUH conllevó en sus inicios como cambio, entendido como "posibilidad y derecho" (Freire, 1997, p. 35), no ha resultado una cosa menor, ya que se ha podido advertir cómo se cristalizó en un derecho transitado, y que, acompañado -en el mejor de los casos- por procesos de concientización en las familias, devino en un derecho conquistado $y$, por ello, defendido y por defender.

En este sentido, el estudio permitió reconocer que muchos padres y muchas madres -por sí solos-, y en ocasiones motivados por la presencia fuerte de alguna docente, inician este tipo de cambios más profundos en la construcción de nuevos destinos con el ejercicio de un oficio responsable y comprometido, la adquisición de nuevos usos, costumbres y hábitos vinculados con la AUH.

Los actores entrevistados reconocieron diversos usos de la AUH que estarían contribuyendo a crear mejores condiciones para la escolarización de los niños. Usos que, en algunos casos, se visualizan como parciales y, en la mayoría, como verdaderos impulsos para la permanencia de los niños y las niñas en las escuelas y para mejorar sus trayectorias escolares. Se advierten, también, crecientes procesos de concientización acerca del uso de la AUH para mejorar las condiciones educativas y de salud de sus beneficiarios, proceso en el cual juegan un importante papel los actores escolares.

Por otra parte, se advierten algunos problemas en la implementación de la AUH como conflictos entre quiénes la reciben o administran en el seno familiar o la necesidad de seguimientos más exhaustivos. Así, la información relevada permite sugerir algunas orientaciones que permitirían mejorar la implementación de esta política social y que enunciamos a continuación. 
En este sentido, se plantea como necesidad realizar acciones culturales y educativas sostenidas en el tiempo, que acompañen a las madres y los padres y las familias para mantener este proceso de asumir niveles crecientes de responsabilización y concienciación sobre la AUH. Esta plataforma de soporte cultural a los padres que administran la AUH para sus hijos se sustentaría en la esperanza arraigada en las posibilidades concretas que emergen del potencial de cambio de las situaciones vividas por ellos (niños, niñas, madres, padres). Sería posible repensarlas a partir de su acompañamiento.

Se insiste en esta posibilidad a través de la creación de equipos multisectoriales y multidisciplinarios que conformen plataformas de cooperación para la promoción de una concienciación creciente de los padres y las madres. Se trataría de un espacio para pensar la educación como especificidad humana que implica la intervención en el mundo y que procura cambios en la sociedad, de los cuales las propias familias son también responsables y dinamizadoras.

Este soporte cultural y educativo, así como este trabajo colaborativo con los padres y las madres, podría ser llevado a cabo por organismos del Estado, organizaciones sociales y profesionales formados en la universidad pública en disciplinas como el trabajo social, la psicología social comunitaria, la sociología, la pedagogía, la comunicación y la psicopedagogía comunitaria. Una posible metodología podrían ser talleres para trabajar colectivamente desde dinámicas de grupos que promuevan la problematización de sus tareas, de su situación concreta como padres, su modo de vivir, para promover la toma de conciencia, la construcción de un nuevo conocimiento y sus posibilidades de transformar las vivencias más próximas que ellos perciben como problema. Se trata de promover mecanismos cuya premisa sea leer y comprender la realidad social en que están insertas estas familias, tarea que permitirá mantener coherencia entre lo que se les exige y lo que ellos viven.

Otra labor de este equipo intersectorial sería acompañar, observar y velar por el cumplimiento de las condiciones que exige la AUH. También debería registrar, monitorear y valorar cómo se implementa esta política social desde un accionar que esté orientado al amparo de la $\mathrm{AUH}$ en el sentido de favorecer y proteger que su misión y lo que conlleva a las familias sea efectivamente realizada.

Trascender la reflexión hacia el impacto en las diversas relaciones humanas, en los derechos humanos -como el derecho al trabajo, a la salud, a la educación, a la tierra-, desde la intencionalidad más amplia de movilizar las historias personales y la historia social para promover una realidad inclusiva y justa para todos, es una posibilidad histórica que tiene esta política social. Es por ello que resulta ineludible el sostenimiento de la AUH en el tiempo como política de Estado, siempre en clave de derecho universal, de ampliación de lo público y responsabilidad indelegable del Estado. 


\section{Referencias bibliográficas}

Agis, E., Cañete, C. \& Panigo, D. (2013, tercer trimestre). Empleo, desempleo y políticas de empleo. El impacto de la asignación universal por hijo en la Argentina. Presentación formal de los resultados anticipados en 2010. Empleo, desempleo y políticas de empleo, 15. Recuperado el 19 de enero de 2019, de: http://www.ceilconicet.gov.ar/wp-content/uploads/2013/12/edpe15.pdf.

Arcidiácono, P., Carmona Barrenechea, V. \& Straschnoy, M. (2011). La asignación universal por hijo para protección social: rupturas y continuidades, ¿hacia un esquema universal? Revista Margen, 61, 2-16. Recuperado el 4 de febrero de 2019, de: http://www.margen.org/suscri/margen61/straschnoy.pdf.

Argentina. Ministerio de Salud y Desarrollo Social (2019). Resolución 11/2019. Recuperado el 4 de agosto de 2019, de: http://servicios.infoleg.gob.ar/ infolegInternet/anexos/325000-329999/326006/norma.htm.

Argentina. Poder Ejecutivo Nacional (2009). Decreto 1602/09. Asignación Universal por Hijo. Recuperado el 29 de enero de 2019, de: https://www.ilo.org/dyn/ travail/docs/1804/DECRETO\%201602.pdf.

Bustos. M., Giglio, G., \& Villafañe, S. (2012). Asignación Universal por Hijo: alcance e impacto por regiones del país. Trabajo, ocupación y empleo. Investigaciones sobre Protección Social y Relaciones Laborales Argentina 2012. Serie Estudios/11. Ministro de Trabajo, Empleo y Seguridad Social. Recuperado el 21 de enero de 2019 de: http://www.trabajo.gob.ar/downloads/estadisticas/ toe_11_completo.pdf\#page $=17$.

Castel, R. (1995). De la exclusión como estado a la vulnerabilidad como proceso. Archipiélago, 21, 27-36.

Dyson, A. (2001). Dilemas, contradicciones y variedades de la inclusión. En M. Verdugo \& F. Jordán de Urríes (Eds.), Apoyos, autodeterminación y calidad de vida (pp. 145-160). Salamanca: Amarú.

Freire, P. (1993). Pedagogía de la esperanza. México: Siglo XXI.

Freire, P. (1997). Pedagogía de la autonomía. México: Siglo XXI.

Gluz, N. \& Rodríguez Moyano, I. (2013). Asignación Universal por Hijo, condiciones de vida y educación. Las políticas sociales y la inclusión escolar en la provincia de Buenos Aires. Archivos Analíticos de Políticas Educativas, 21(21). Recuperado el 3 de febrero de 2019 de: http://epaa.asu.edu/ojs/article/view/1102.

Krichesky, M. (2009) Dispositivos para la inclusión. Entre la periferia y la centralidad de la escuela. En G. Misirlis (Comp.), Todos en la escuela. Pensar para incluir, hacer para incluir (pp. 127-137). Buenos Aires: Unsam Edita.

Macchiarola, V., Martini, C., Montebelli, A. \& Mancini, A. (2018, abril-junio). Nuevos formatos escolares para la inclusión educativa en Argentina. Revista Innovación Educativa, 18(77), 183-207. 
Parrilla Latas, A. (2002). Acerca del origen y sentido de la educación inclusiva. Revista de Educación, 327, 11-29.

Perassi, Z. \& Macchiarola, V. (Coord.). (2018). Políticas de inclusión educativa. La evaluación del impacto de algunas experiencias en Argentina. Buenos Aires: Miño y Dávila.

Sendón, M. A. (2012). El imperativo de la inclusión escolar y la proliferación de significados acerca de la escolarización secundaria. En G. Tiramonti (Dir.), Variaciones sobre la forma de lo escolar. Límites y posibilidades de la escuela media (pp. 155-178). Santa Fe: FLACSO. Homo Sapiens. 